\title{
Patient and port positioning in laparoscopic liver resections
}

\author{
Nita Thiruchelvam ${ }^{1}$, Ser Yee Lee ${ }^{2,3}$, Adrian Kah Heng Chiow ${ }^{1}$ \\ 'Department of General Surgery, Hepatopancreatobiliary Service, Changi General Hospital, Singapore 529889, Singapore. \\ ${ }^{2}$ Department of Hepatopancreatobiliary and Transplant Surgery, Singapore General Hospital, Singapore 169608, Singapore. \\ ${ }^{3}$ Surgical Associates, Mount Elizabeth Medical Centre, Singapore 228510, Singapore.
}

Correspondence to: Dr. Nita Thiruchelvam, Department of General Surgery, Hepatopancreatobiliary Service, Changi General Hospital, 2 Simei Street 3, Singapore 529889, Singapore. E-mail: thiruchelvam.nita@singhealth.com.sg

How to cite this article: Thiruchelvam N, Lee SY, Chiow AKH. Patient and port positioning in laparoscopic liver resections. Hepatoma Res 2021;7:22. http://dx.doi.org/10.20517/2394-5079.2020.144

\author{
Received: 9 Nov 2020 First Decision: 24 Dec 2020 Revised: 17 Jan 2021 Accepted: 29 Jan 2021 Published: 12 Mar 2021 \\ Academic Editors: Ho-Seong Han, David Geller Copy Editor: Yue-Yue Zhang Production Editor: Xi-Jun Chen
}

\begin{abstract}
Currently, laparoscopic liver resections are routinely performed at an increasing number of centres and has extended to include major liver resections as well as more challenging segments of the liver. We believe that patient positioning and port placement is a critical yet under described component of successful laparoscopic liver resection to achieve optimal visualisation and allow for an ergonomic and safe dissection. In this article, we describe the advantages of various types of patient positioning as well as provide illustrations for an array of trocar configurations previously described in literature. Whilst there is no universally accepted standardization of port placement for various resection types, this descriptive article can serve as a guide for the various possibilities of port configurations that can be individually adapted by surgeons based on their preference as well as the patient's physique and anatomy.
\end{abstract}

Keywords: Laparoscopic liver resection, port positioning, patient positioning

\section{INTRODUCTION}

In the first and second international consensus conference held in Louisville and Morioka in 2008 and 2014 respectively, minor laparoscopic liver resections (LLR) were acknowledged to be the standard of care and major resections were deemed to be in the exploratory phase ${ }^{[1,2]}$. Since then, with improved technology, increased surgical experience, and introduction of novel techniques, an international survey revealed

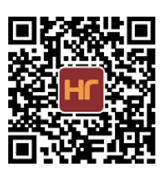



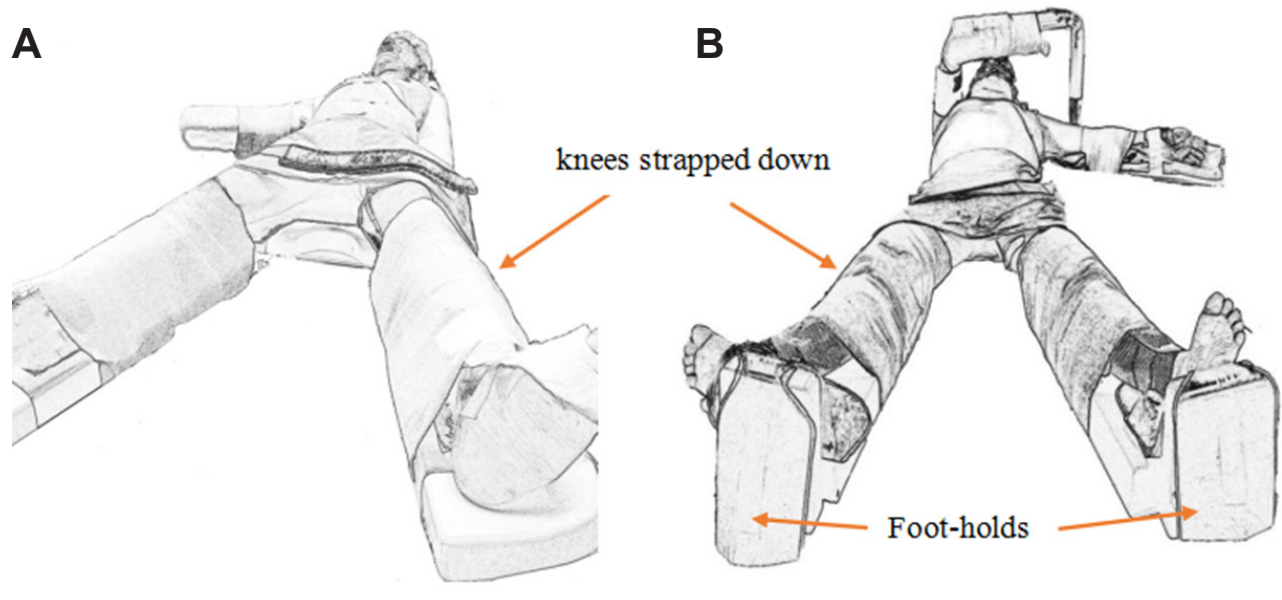

Figure 1. Supine straight split-leg position. The right arm is extended on an arm-board (A). The right arm is abducted and flexed overhead in an arm support, which facilitates port placement for posterior-superior resections (B).

that the indications for laparoscopic liver resections involving all liver segments have expanded ${ }^{[3]}$ and an increasing number of centres have adopted it as routine practice ${ }^{[4-6]}$.

The liver's shielded anatomical location beneath the ribs traditionally requires extended subcostal incisions for surgical access in open surgery, whereas in LLR, ideal patient and port positioning have facilitated optimal laparoscopic visualization with ergonomical access. The caudal approach is the main paradigm shift in LLR, in contrast to the anterior approach adopted during open liver resections. These magnified caudal views not only allow for enhanced and precise parenchymal transection of the liver, but also facilitate improved exposure of the hilar plate for pedicle clamping, and around the right adrenal gland and the inferior vena cava for meticulous division of the short hepatic veins ${ }^{[7,8]}$.

This article seeks to summarize and illustrate the options available for patient and port positioning in varying types of LLR, which we believe is an under-described, yet a critical technical aspect in LLR.

\section{PATIENT POSITIONING}

The planned liver resection and surgical approach will dictate the ideal patient positioning and port placement. Liver resections are broadly divided into non-anatomical partial hepatectomies, or anatomical segmentectomies, sectionectomies or hemihepatectomies, whereby resection lines follow the portal inflow and hepatic veins. We describe patient positioning in the context of planned surgical resection, as follows.

\section{Laparoscopic liver resection for antero-lateral segments}

Supine straight split-leg position

A frequently adopted position for this large subset of LLR is the supine straight split-leg position [Figure 1]. This position facilitates more ergonomical options of standing positions for the primary surgeon and the assistants, by allowing one to stand between the patients' legs, and has been affectionately termed the "French position$^{[9,10]}$.

The knees are strapped to prevent buckling when the patient is subsequently positioned in steep reverse Trendelenburg. Additional foot-holds can prevent the patient from sliding caudally [Figure 1B]. The upper limbs are typically extended or flexed overhead to allow for more lateral trocar placement, as well as to add stability to the patient's position during left-right axis tilting. Arm-boards also provide easy vascular access to the upper limbs for anaesthesiologic purpose. 


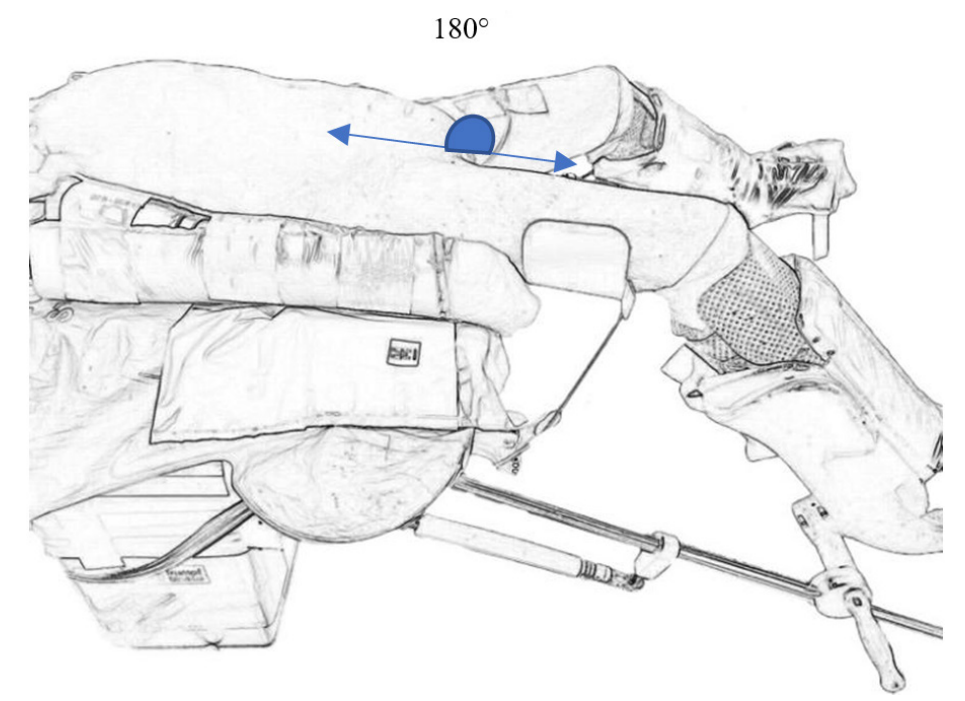

Figure 2. Modified Llyod-Davies position. Care must be taken to ensure that the legs sit comfortably in the stirrups to reduce pressure on the common peroneal nerve. Ideally, the hip is maintained in neutral flexion-extension position to prevent clashing of the laparoscopic instruments with the patient's thigh intra-operatively.

\section{Modified Lloyd-Davies position}

The modified Lloyd-Davies position with leg stirrups can also be utilised should the straight-leg split surgical table not be readily available, or should there be a need for access into the pelvis/perineum such as in the setting of combined colorectal and liver resections for colorectal cancer with liver metastasis [Figure 2]. In both the supine straight split leg or modified Llyod-Davies position, the patient can be placed on a gel mattress that has anti-slip properties or a vacuum-cushion mattress that is moulded to the patient's body contours to prevent the patient from sliding once placed in reverse Trendelenburg or if the surgical bed is tilted in the left-right axis.

Pneumatic thigh and calf compressors should be utilised to minimize deep venous thrombosis of the lower limbs, which is particularly important in laparoscopic liver resection wherein patients are subjected to reverse Trendelenburg positioning for extended periods.

\section{Laparoscopic liver resections for posterior and superior lesions}

\section{Left lateral decubitus}

The left lateral decubitus is commonly employed for posterior lesions in segment 6, segment 7 and dorsal aspect of segment $8^{[11,12]}$ [Figure $3 \mathrm{~A}$ and $\mathrm{B}$ ]. Not only does this position offer better exposure of posterior segments, but it elevates the right hepatic vein higher than the vena cava, which reduces hepatic venous bleeding ${ }^{[7,13]}$. With adjustment of the left-right rotation of the operating table to achieve a more supine position, the surgeon is allowed flexibility to access the liver hilum for portal inflow isolation or application of a snare around the hepatoduodenal ligament for the Pringle's manoeuvre.

Typically, in a full left lateral decubitus position the legs are not split. However, in instances where a full left lateral decubitus is not required and the surgeon would still like to maintain a split-leg position, one can modify the original supine split-leg or modified Lloyd-Davies position [Figures 1 and 2] to include a gentle 30 to 45 -degree tilt with the use of gelpads placed under the right side of the abdomen.

\section{Semi-prone position - a modification of the left lateral decubitus position}

The semi-prone positioning is a modification of the left lateral decubitus position, and has also been described for right-sided hepatectomies in particular segment 6, 7, 8 resections, posterior sectionectomy, 

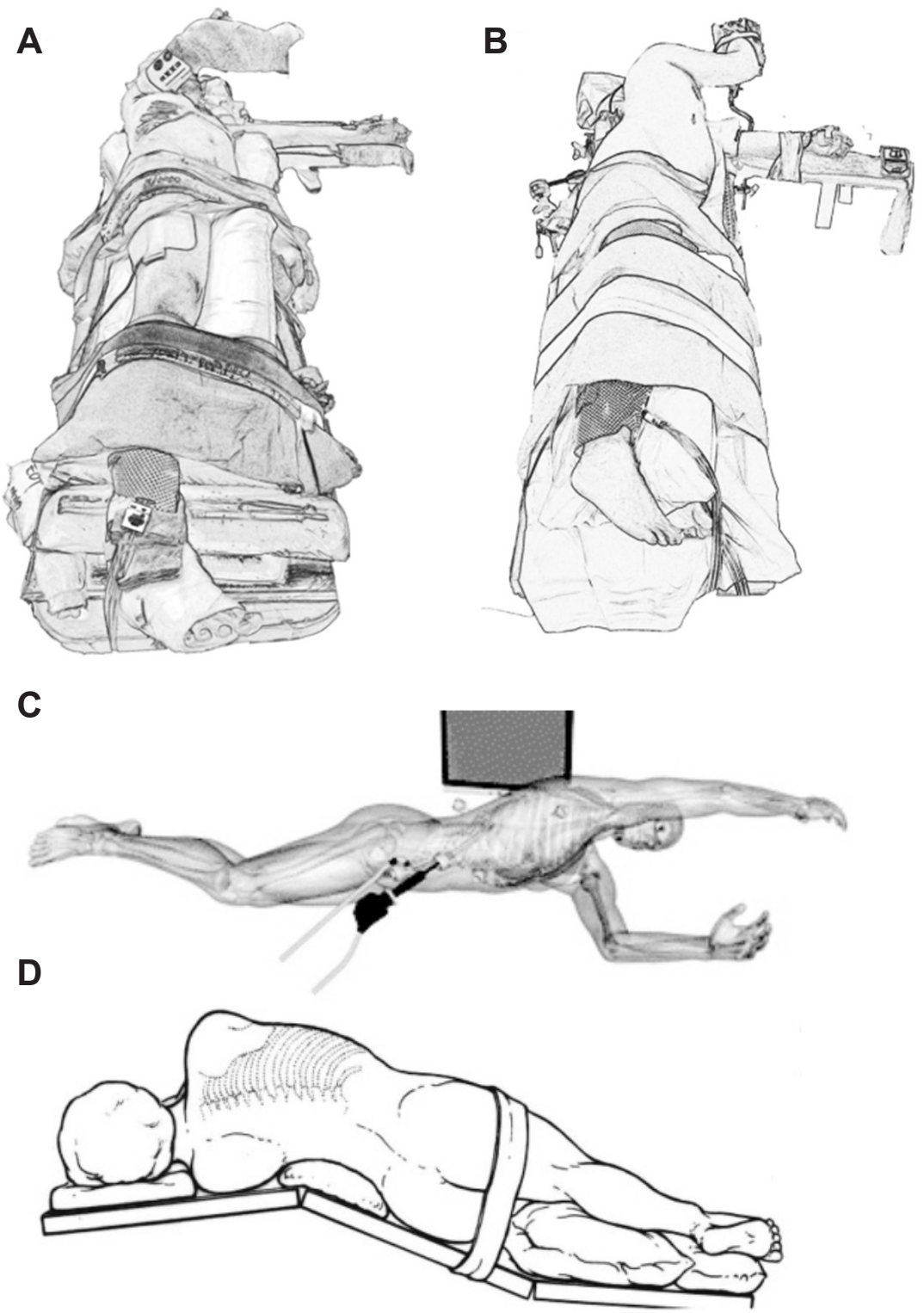

Figure 3. Patient positioning for laparoscopic liver resections for posterior and superior lesions. Left semi-lateral decubitus (30-45 degree tilt) (A). Full left lateral decubitus Semi-prone position described by lkeda et al. ${ }^{[15]}$ (B). Semi-prone position described by lkeda et al. ${ }^{[16]}$ (C). Left jack-knife position ${ }^{[17]}$ (D). http://creativecommons.org/licenses/by/4.0.

right-sided caudate lesions, and right hepatectomy ${ }^{[14-16]}$. This semi-prone position can be adopted by rotating the operating table 20-25 degrees with a patient positioned in the left lateral decubitus, resulting in a position best described by Ikeda et al. ${ }^{[16]}$ as a swimmer breathing during a front crawl swim [Figure $3 \mathrm{C}$ ].

Once the right lobe of the liver is completely mobilized, retraction of the right lobe of the liver to the right and cranially allows improved visualisation of hilar structures; in particular, the main portal fissure, right portal fissure, and portal fissure of the caudate process ${ }^{[15]}$. The stomach, duodenum, and colon similarly hang down toward the left, facilitating the Glissonian approach to the right lobe.

Although the semi-prone position has been described for right hepatectomy, this may not be replicable in the context of large right lobe tumours because manipulation of the right lobe will be difficult, resulting in poor visualisation of the porta hepatis. In this scenario, the conventional supine straight split-leg position with anterior caudal approach is more appropriate. 
Conversion from laparoscopic to open surgical approach in the semi-prone position can still be achieved by rotating the operating table to a neutral position, and a right subcostal incision can then be made in the left lateral decubitus position ${ }^{[15]}$.

\section{Left jack-knife position}

The left jack-knife position involves adjusting the operating table at the level of the lumbar region to an angle of approximately 120 degrees, once the patient is already in a left lateral decubitus position [Figure $3 \mathrm{D}]^{[17]}$. Lumbar extension increases the operating field by widening the distance between the right costal margin and the right anterior superior iliac spine, allowing wider space for lateral port placement.

\section{Reverse trendelenburg}

In addition to all these varying positions, a reverse Trendelenburg, which can range from 10-30 degrees is also simultaneously adopted. This serves to decrease hepatic venous pressure by reducing venous return, and also improves caudal exposure by gravitationally shifting visceral structures away from the liver hilum $^{[2]}$.

\section{A TYPICAL OPERATION THEATRE SET-UP}

This is an example of a typical operation theatre set-up [Figure 4]. Depending on the type of surgery, the patient's positioning may vary (legs together $v s$. legs split), and the main surgeon may switch positions to be on the patient's right or left.

Dual air supply is recommended routinely for laparoscopic liver resection as it negates the sudden loss of pneumoperitoneum when there is more liberal use of the surgical aspirator in the context of bleeding. An alternative to dual air supply is the use of valve-less trocar systems, which is able to maintain a stable pneumoperitoneum with laminar flow and carbon dioxide recirculation in spite of high flow suction or airleak.

Providing a template of the operation theatre layout allows the surgeons, nursing staff, and OT attendants to plan accurate placements of surgical equipment, optical screens, and appropriate energy device foot pedals, enhancing the overall efficiency of the set-up for LLR.

\section{PORT PLACEMENT}

There is no standard for port positioning in LLR even in surgeries that are as routinely performed as left lateral sectionectomies, and tweaks are often necessary depending on each unique case ${ }^{[9,18]}$. In a typical LLR, up to 4-6 ports may be used, with a minimum of two $12 \mathrm{~mm}$ ports - one for the preferred flexitip (e.g., Olympus EndoEye; Olympus Medical System Corp, Tokyo, Japan) or 30-degree camera, and an additional as a working port for the insertion of the laparoscopic ultrasound probe, stapler, and ultrasonic aspirator, amongst other $10 \mathrm{~mm}$ instruments. In our experience, 3D imaging capability can be useful in improving depth perception, especially in the context of deep parenchymal transection.

Specimen retrieval sites are typically an extension of the para-umbilical incision or a pfannenstiel incision for larger specimens. The pfannenstiel incision provides improved cosmetic outcome and reduced postoperative pain.

In the straight split-leg or modified Llyod-Davies position, the first port placement is most commonly a supraumbilical $12 \mathrm{~mm}$ port with additional working ports then placed along a diameter of concentric circles radiating from the tumour ${ }^{[19]}$. The position of the supra-umbilical port can also vary in distance from the umbilicus, accommodating for patients with a longer xiphisternum-umbilical distance. An 


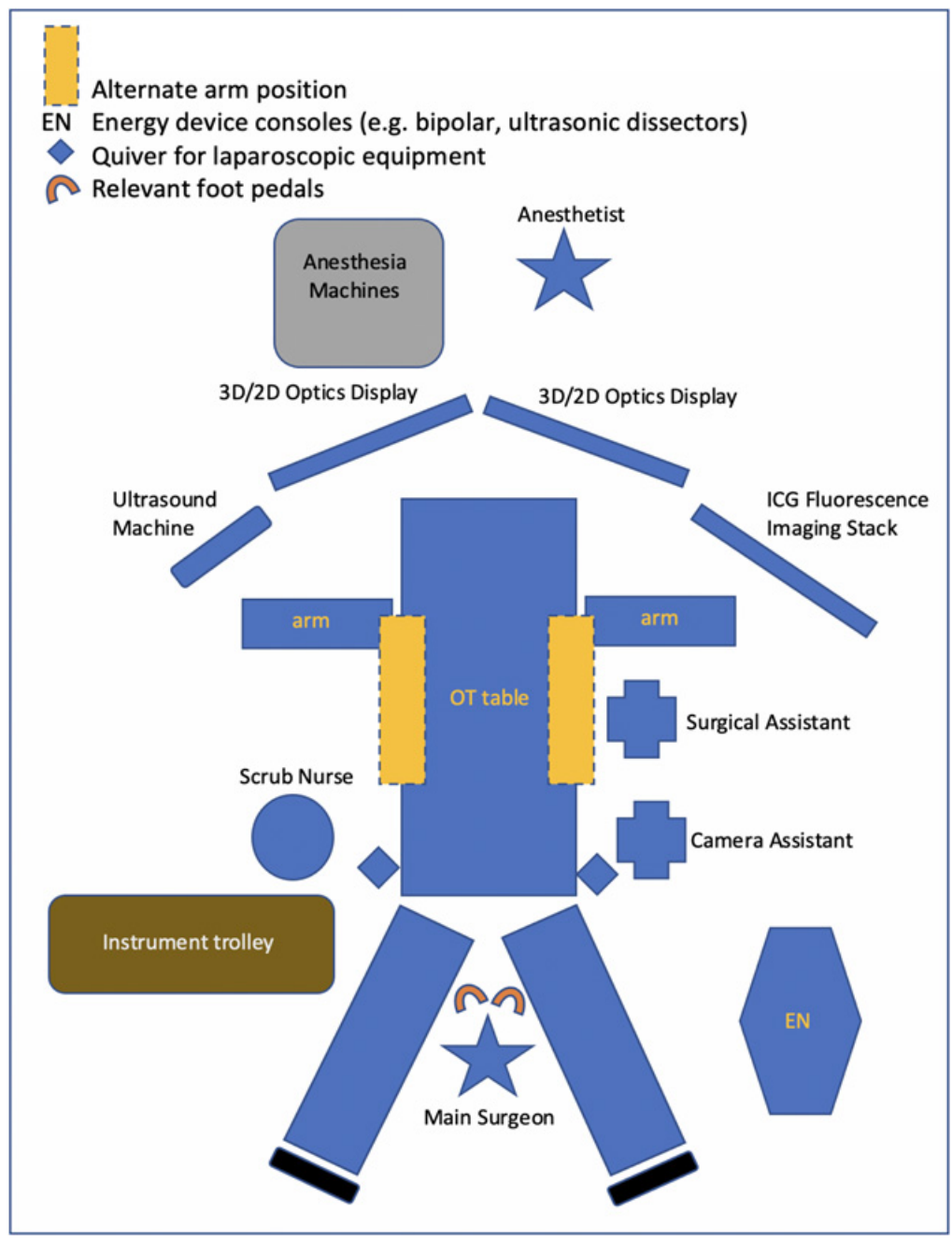

Figure 4. A typical operation theatre set-up.

infra-umbilical port is a useful alternative in the context of a cirrhotic patient to avoid potential bleeding from the recannulated umbilical vein. In instances where the resection plane is predicted to extend more superiorly and posteriorly, the optical trocar port can be inserted in the upper right paramedian instead.

In patients with high body mass index, port placements are best referenced from fixed anatomical landmarks such as the xiphisternum and the costal margin rather than the umbilicus. In contrast, patient's with hepatomegaly from severe steatosis or alcoholic liver disease would require port placements to be inferiorly translocated away from the costal margins to account for a more inferior liver edge. In the event that an LLR is attempted on a patient with previous open surgery, index port placement is often the safest via a open cut-down technique at a site away from the previous incisions, with additional ports placed for adhesiolysis prior to the intended LLR port configuration for the planned liver resection. For repeat LLRs, omental and bowel adhesions are less common; this upfront allows for port placement of a desired configuration after initial laparoscopic survey through the optical trocar. However, the liver hilum may be scarred if it was previously dissected, and the liver tends to be adherent to the diaphragmatic and retroperitoneal surfaces if it was previously mobilised.

In the event that the surgeon's preference is an extracorporeal Pringle manoeuvre, a short profile $5 \mathrm{~mm}$ trocar is often utilised for convenience, such that it will not interfere with the resection and also allow 


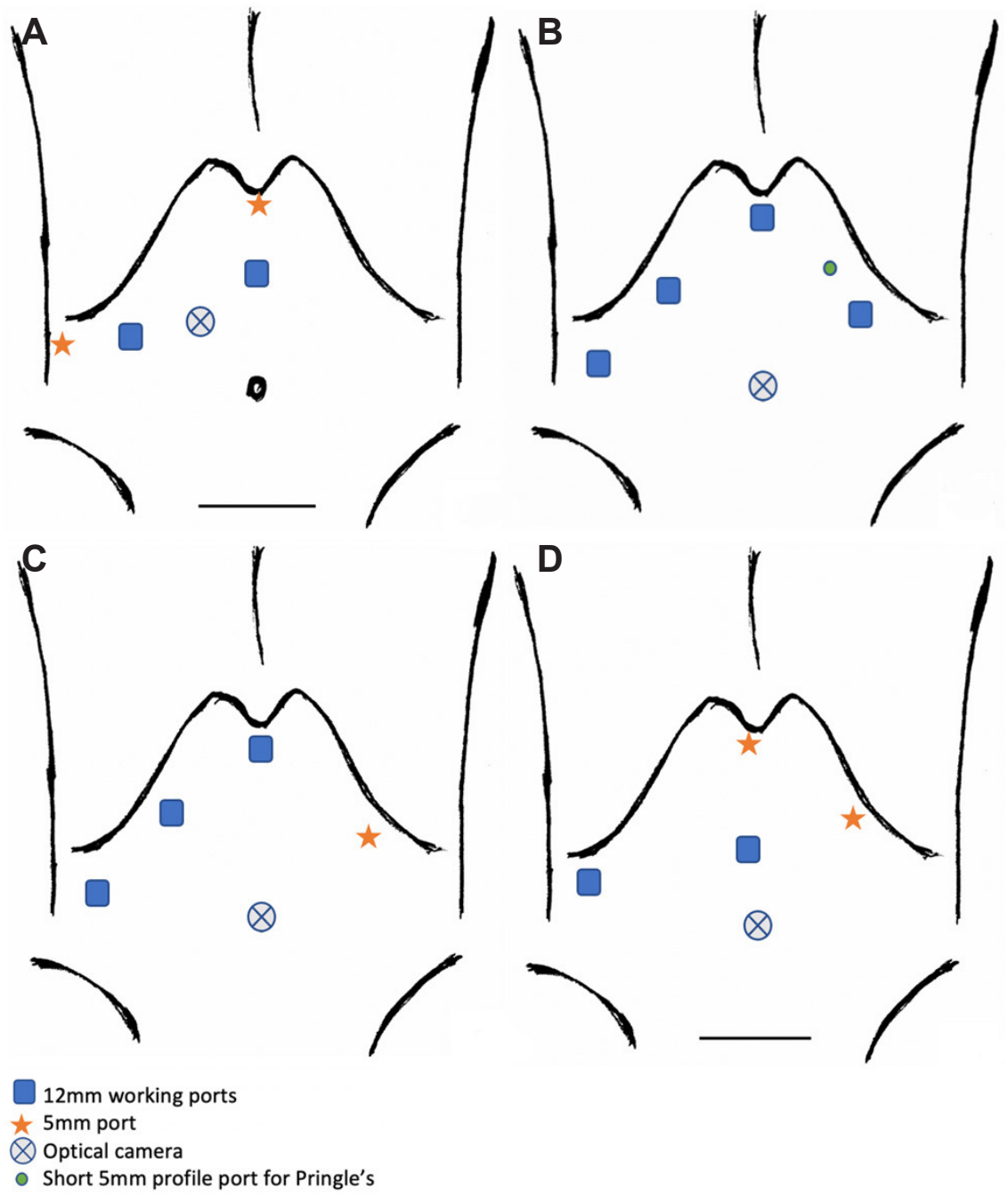

Figure 5. Laparoscopic right/left hepatectomy including living donor liver transplant (LDLT). The use of 5-6 trocars for laparoscopic right hepatectomy proposed by Soubrane et al. ${ }^{[8]}$ (A). Port placements utilised for laparoscopic right hepatectomy for HCC with bile duct tumour thrombus ${ }^{[20]}$ (B). Port placements for LDLT for both right and left hepatectomy described by surgeons from Seoul National University Hospital, South Korea ${ }^{[21-23]}$ (C). Port placements for LDLT for right hepatectomy described by surgeons from Samsung Medical Centre, South Korea ${ }^{[24,25]}$ (D).

for rapid application and release of the tourniquet. In some instances, surgeons may prefer to exteriorise the tourniquet through the abdominal wall without a port, however, care must be taken to ensure a snug incision such that there is no leakage of pneumoperitoneum.

Here, we provide examples of previously described port placements for varying resection types.

\section{Resections typically performed in the supine (split-leg or modified Llyod-Davies) position}

Laparoscopic right/left hepatectomy including living donor liver transplant

An optical camera is placed along the anterior axillary line to align the resection line along the Cantlie line. Pfannenstiel incision is used for specimen extraction. Pringle's manoeuvre is applied, if required [Figure 5A].

In patients with a smaller abdominal domain, it may be difficult to achieve adequate spacing between the 4 main subcostal ports, as in Figure 5A, hence the assistant working port can be shifted to the left subcostal margin [Figure 5B]. 

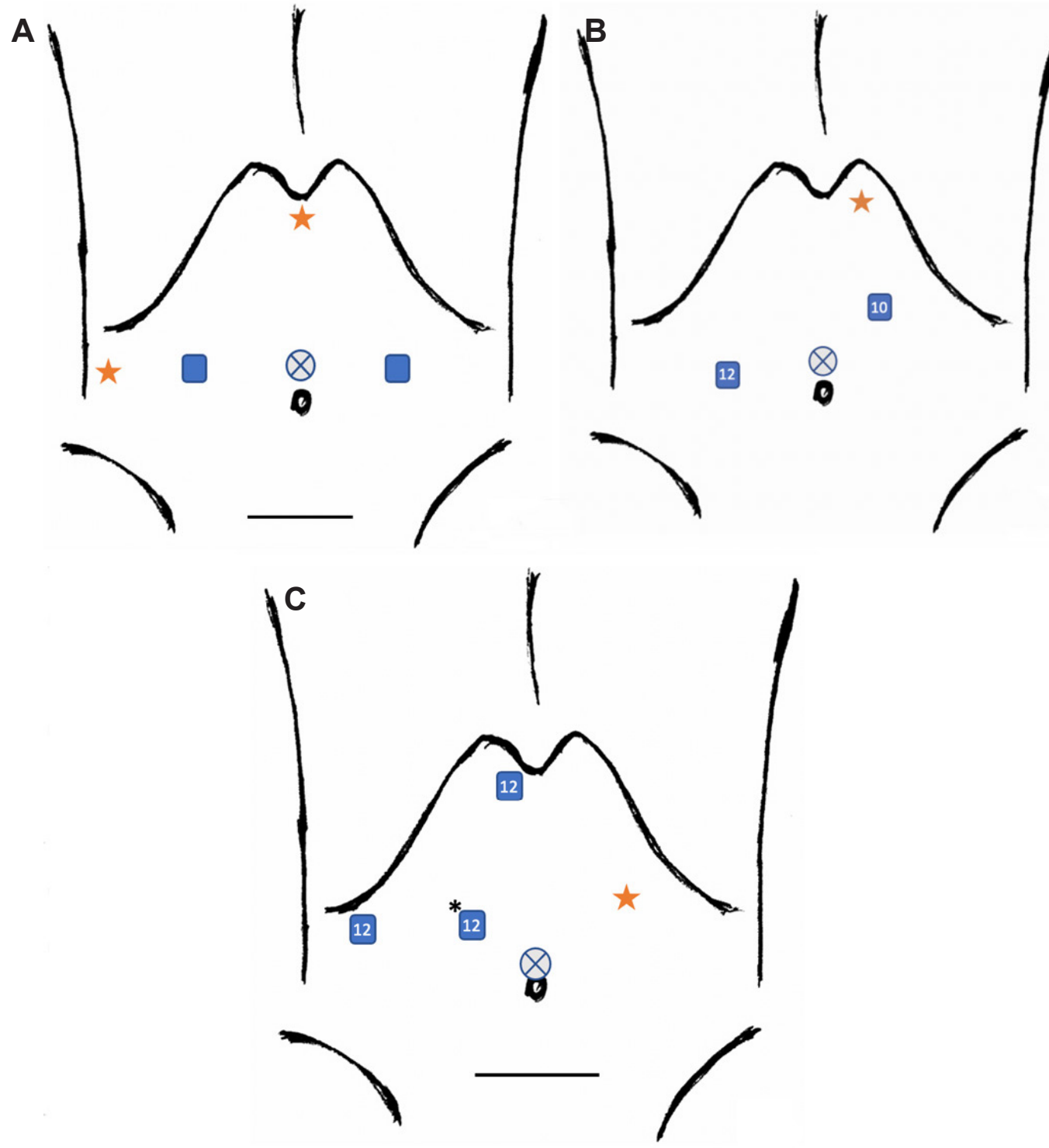

$10 / 12 \mathrm{~mm}$ working ports

$\star 5 \mathrm{~mm}$ port

Optical camera

Figure 6. Laparoscopic left lateral sectionectomy. Common port placement described by experienced French teams for left lateral sectionectomy $(\operatorname{LLS})^{[9,26]}(A)$. Port placements for LLS and LDLT LLS by Troisi et al. ${ }^{[27]}$ (B). Port placements for LDLT LLS by Kim et al. ${ }^{[28]}$ at University of Ulsan College of Medicine and Asan Medical Centre (C).

No Pringle’s manoeuvre utilised [Figure 5C].

The two $12 \mathrm{~mm}$ ports are utilised as the surgeon's main working ports in the right anterior axillary line and the midline. The port sites vary slightly based on an individual patient's profile. Pringle's manoeuvre was used at the surgeon's discretion [Figure 5D].

\section{Laparoscopic left lateral sectionectomy}

The supraumbilical optical trocar can be shifted further away from the umbilicus based on the patient's xiphoid-umbilical distance. The $5 \mathrm{~mm}$ epigastric port is variable [Figure 6A]. 


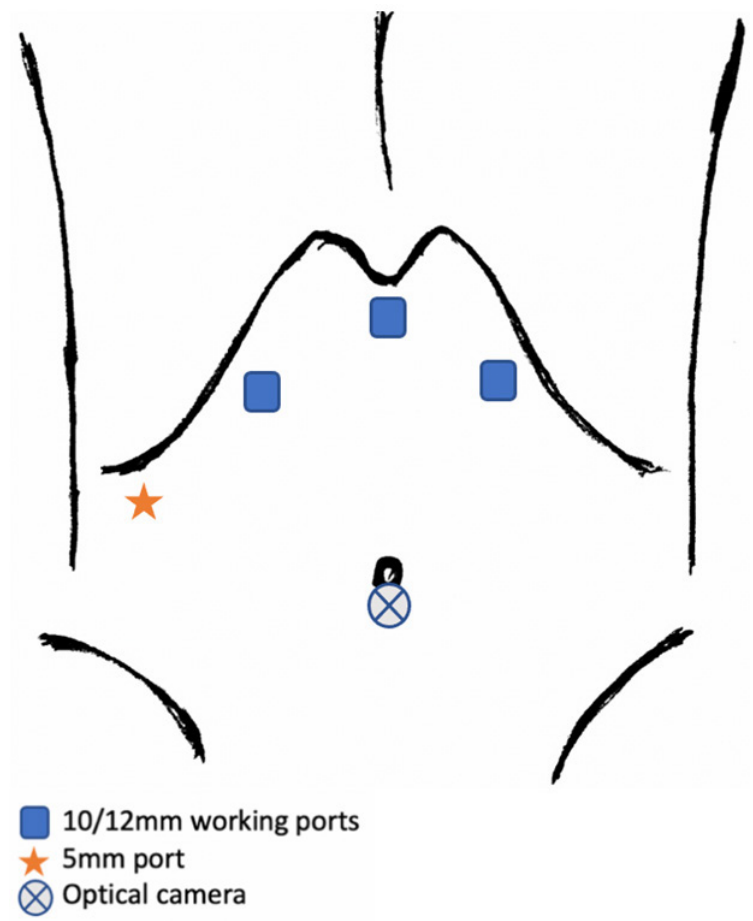

Figure 7. Port placement for laparoscopic S4, subsegments S4a, S4b, and extended S4 by Kim et al. ${ }^{[29]}$.

The $5 \mathrm{~mm}$ subxiphoid port allows irrigation, aspiration, as well as liver hanging where necessary. Two 12 $\mathrm{mm}$ ports are utilised for an optical trocar and working port mainly to facilitate use of the linear stapler. A $10 \mathrm{~mm}$ working port is utilised for the harmonics scissors or surgical aspirator. Similar port set-up is utilised for LDLT focused on LLS [Figure 6B].

No Pringle manoeuvre utilised [Figure 6C].

\section{Laparoscopic segment 4 resection}

The patient is positioned supine with modified Llyod-Davies with the main surgeon between the patient's legs. Medial resection proceeds along the right side of the falciform ligament with subsequent $\mathrm{S} 4 \mathrm{a}$ and S4b pedicle control. Second transection line is along the ischemic line or $1 \mathrm{~cm}$ beyond the MHV where extended 44 is required [Figure 7].

\section{Laparoscopic central bisectionectomy and right anterior sectionectomy}

The patient is placed supine with a slight right tilt, legs together. The surgeon and scopist stand on the patient's left, whilst the assistant stands on the surgeon's right. Optical trocar is placed $3-4 \mathrm{~cm}$ away from the umbilicus [Figure $8 \mathrm{~A}$ ]. Rubber band self-retraction technique by Choi et al. ${ }^{[31]}$ is utilised for the two resection planes respectively.

The patient was positioned supine with a right side tilt and the surgeon stood between the patient's legs [Figure 8B].

\section{Resections typically performed in the left lateral, semi-prone or jack-knife position}

In the left lateral, semi-prone, or jack-knife position, a combination of anterior and lateral approach to port placement is adopted, with the possibility of intercostal trocar insertions ${ }^{[16,34-38]}$. The lateral approach with intercostal ports allows for better visualisation and improves the range of motion of instruments to perform parenchymal transection for lesions in segment 7 and 8. 


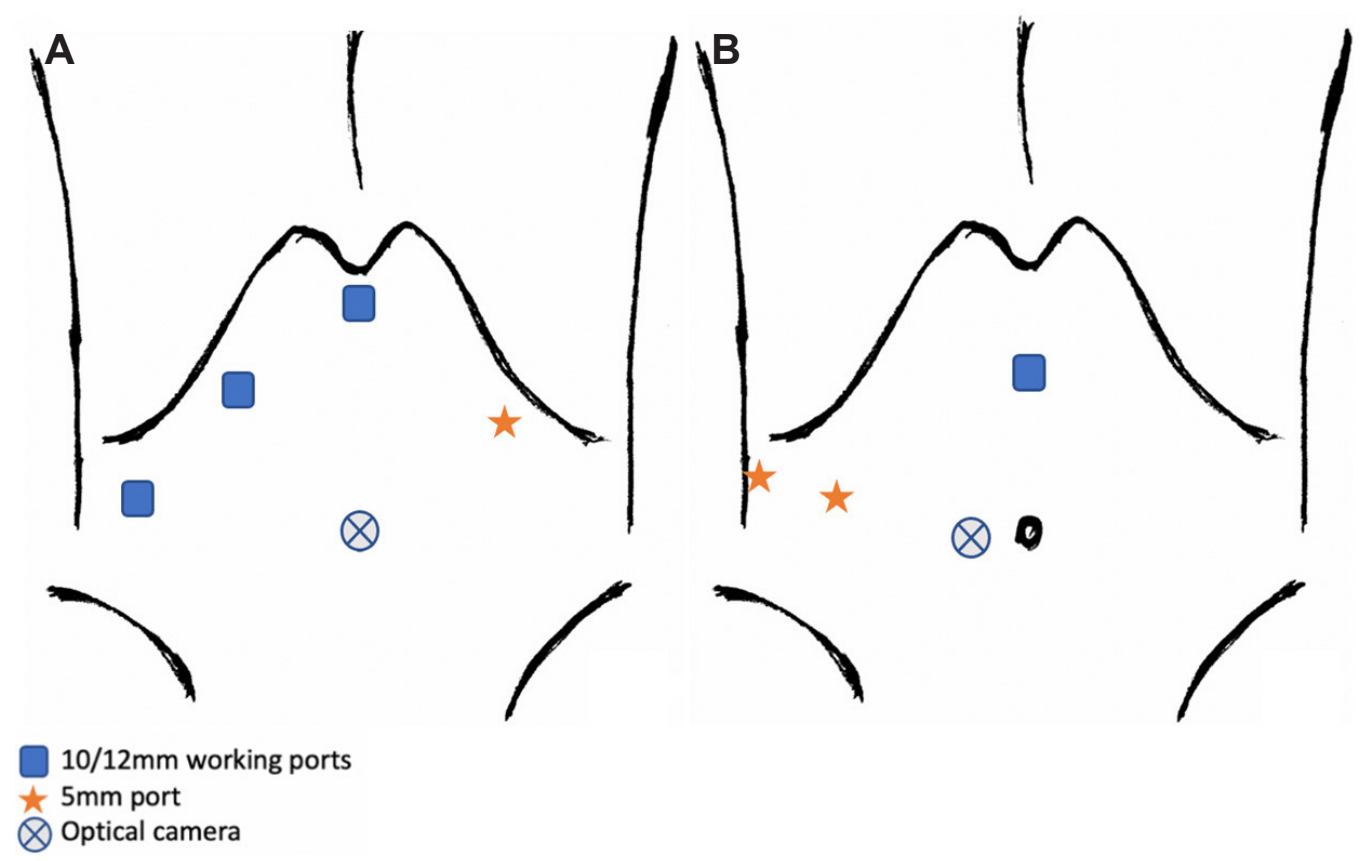

Figure 8. Laparoscopic central bisectionectomy and right anterior sectionectomy. Port placement for laparoscopic central bisectionectomy and right anterior sectionectomy by Jeung et al. ${ }^{[30]}(\mathrm{A})$. Kim et al. ${ }^{[32]}$ and Ho et al. ${ }^{[33]}$ utilised similar port placements for centrally located tumours as that used by Suh et al. ${ }^{[22]}$ in LDLT right/left hepatectomy, described above (B).

Insertion of intercostal ports can be performed using one of the three methods ${ }^{[35]}$ : (1) ports inserted between the ribs below the diaphragm; (2) ports inserted between the ribs and through the diaphragm whereby intra-peritoneal laparoscopic instruments are used to apply pressure on the diaphragm against the chest wall such that the lung is pushed away; and (3) optically inserted transthoracic ports that will require a separate laparoscopic stack to allow sequential entry, first into the thoracic cavity, followed by trans-diaphragm. Balloon-ports are used preferentially as they are able to retract the balloon snugly against the diaphragm, thereby allowing greater working space and minimizing intra-operative pneumothorax formation. These methods of insertion of intercostal ports preclude the need for single lung ventilation. Care must be taken to routinely aspirate residual gas from the thoracic cavity as well as close all primary diaphragmatic port sites after the completion of resection to prevent herniation ${ }^{[36,39]}$.

Laparoscopic resections of dome lesions (segments 7 and 8)

Patient is positioned left lateral with right arm suspended [Figure 9A].

Surgery begins with an abdominal approach with the surgeon standing between the patient's legs or on the patient's left. First optical trocar is placed at the umbilicus with 3 right subcostal working ports.

During the anterior approach: Hepatoduodenal ligament is snared in preparation for Pringle's. Right liver mobilisation is followed by intra-operative ultrasound for margins. Caudal and superficial liver parenchyma are transected. Thereafter, the lateral approach begins with two balloon-tipped trans-diaphragmatic ports inserted through the same right intercostal space, and the surgeon then moves to patient's right. As a modification to this approach, where deemed necessary, additional trans-diaphragmatic intercostal ports at a higher chest entry point are placed for more postero-medially located dome resections ${ }^{[35,40]}$.

Patient is positioned in the left lateral decubitus position with the legs apart [Figure 9B]. Additional transdiaphragmatic trocars are placed along the 9th and 11th intercostal space in the mid-axillary and anterior axillary line. 

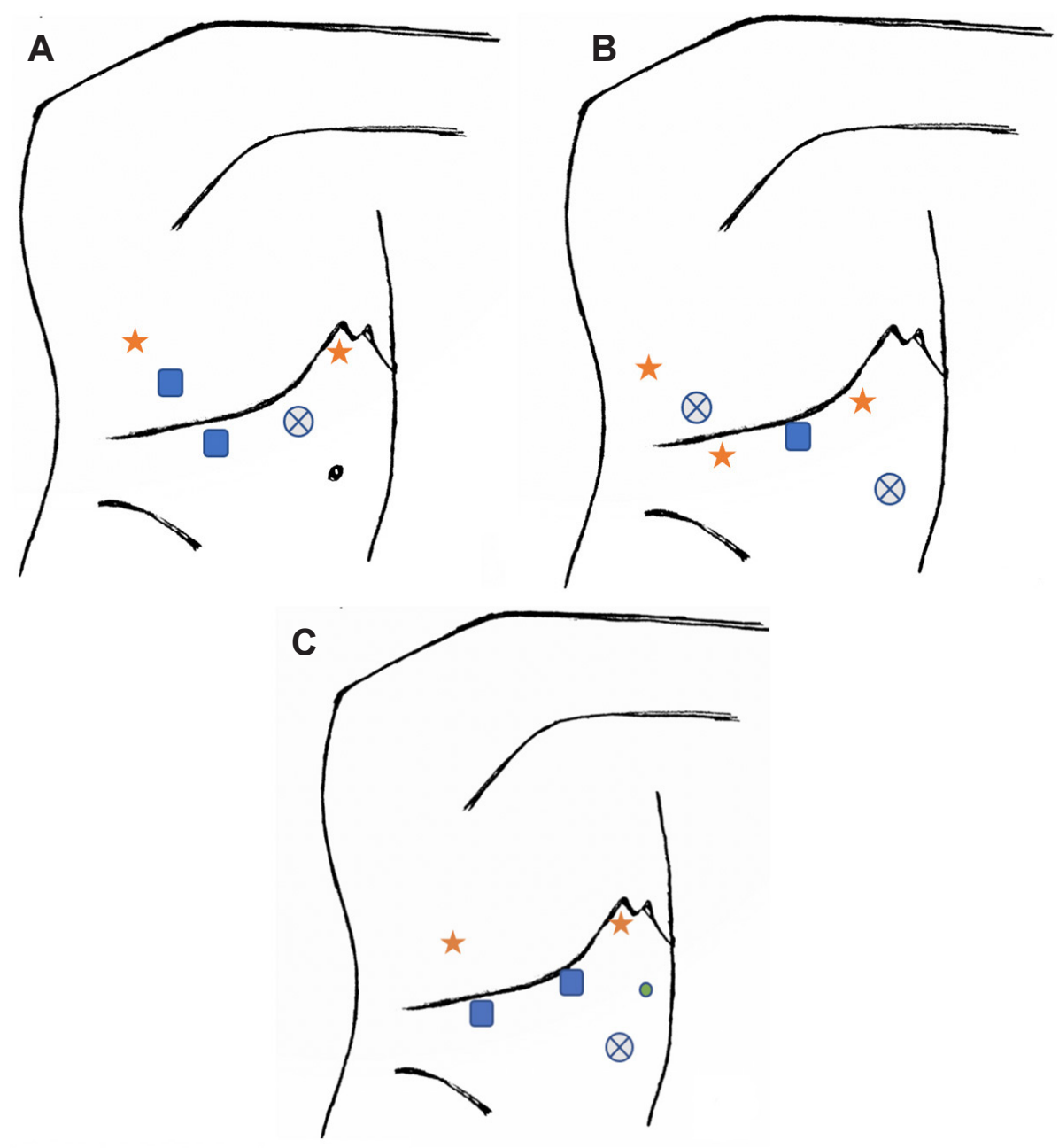

$12 \mathrm{~mm}$ working ports

$\star 5 \mathrm{~mm}$ port

Optical camera

- Short $5 \mathrm{~mm}$ profile port for Pringle's

Figure 9. Laparoscopic resections of dome lesions (segment 7 and 8). Laparoscopic segment 7 or 8 resections using a combined abdominal and lateral approach by Ishizawa et al. ${ }^{[1]}$ and Ogiso et al. ${ }^{[36]}(\mathrm{A})$. An alternative port positioning for posterior liver resections using combined abdominal and lateral approach ${ }^{[40]}(B)$. Port positions for laparoscopic segment 7 resections by Okuda et al. ${ }^{[37]}$ (C).

Patient is positioned in the left semi-lateral [Figure $9 \mathrm{C}$ ]. The main surgeon stands on the patient's right. 5 $\mathrm{mm}$ trocar is placed adjacent to the xiphoid process with additional $12 \mathrm{~mm}$ ports placed 6-7 $\mathrm{cm}$ apart along the right subcostal margin. The operation begins with right lobe mobilisation to increase the sub-phrenic space prior to insertion of an additional $5 \mathrm{~mm}$ trocar in the 9th intercostal space at the right posterior axillary line. This allows for better triangulation and hence access to segment 7, utilising the two lateral working ports.

\section{Laparoscopic right posterior sectionectomy}

The first main $12 \mathrm{~mm}$ trocar is placed $5 \mathrm{~cm}$ above the umbilicus at the right mid-clavicular line. Subsequent placement of $10 \mathrm{~mm}$ infra-umbilical trocar and additional $5 \mathrm{~mm}$ trocars are in the subxiphoid, mid-line, and right anterior axillary line [Figure 10A].

Surgeon stands on the patient's left side, who is positioned at a 45 -degree tilt in semi-lateral decubitus [Figure 10B]. 

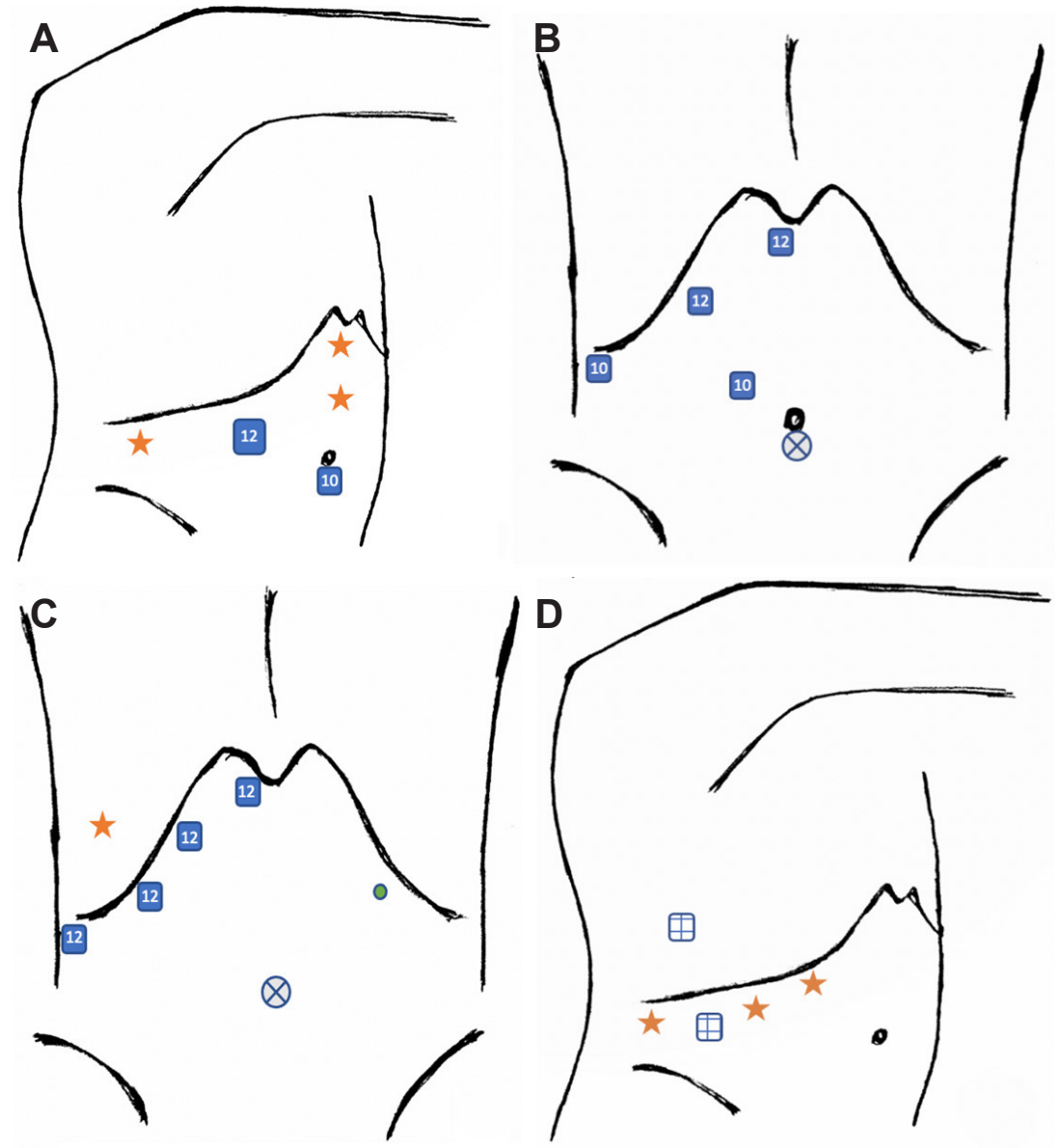

$10 / 12 \mathrm{~mm}$ working port

$12 \mathrm{~mm}$ ports that may interchangeably function as optical trocar/working port

$\star 5 \mathrm{~mm}$ port

Optical camera

- Short $5 \mathrm{~mm}$ profile port for Pringle's

Figure 10. Laparoscopic right posterior sectionectomy. Right posterior sectionectomy in the full left lateral decubitus ${ }^{[41]}$ (A). Right posterior sectionectomy in the semi-lateral decubitus ${ }^{[42]}$ (B). Right posterior sectionectomy in the left semi-lateral decubitus (30-degree tilt $^{[43]}(C)$. Right posterior sectionectomy with use of a trans-thoracic intercostal port ${ }^{[44]}$ (D).

Surgeon stands on the patient's right. Additional $5 \mathrm{~mm}$ balloon-tipped trocar placed in the right 8 th intercostal space in the posterior axillary line. Pringle's manoeuvre may be used at the surgeon's discretion [Figure 10C].

Patient positioned in modified Llyod-Davies with left lateral tilt and right arm overhead. The surgeon stands between the patient's legs. A $12 \mathrm{~mm}$ transthoracic intercostal balloon port is inserted in the 7th intercostal space and can be used interchangeably as the optical trocar [Figure 10D].

Placement of a $12 \mathrm{~mm}$ transthoracic port as shown in Figure 10D is particularly useful for visualisation along the hepatocaval ligament and dissection of the origin of the right hepatic vein at the inferior vena cava.

By positioning the patient in the full left lateral decubitus position, the resection plane for posterior sectionectomy is converted from a horizontal plane to a more vertical plane ${ }^{[45]}$. In these instances, the surgeon may choose not to mobilize the right lobe of the liver - the exposure of the resection plane along 

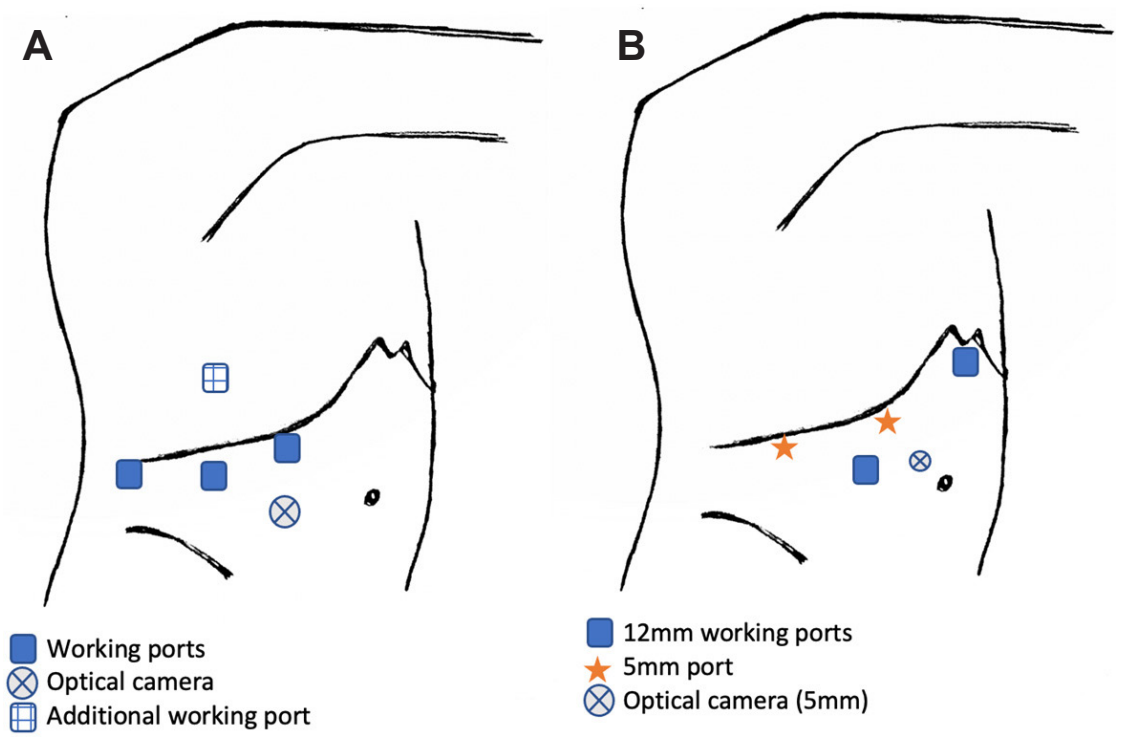

Figure 11. Right-sided resections performed in the semi-prone position. Port positioning by lkeda et al. ${ }^{[16]}$ for right sided resections in the semi-prone position (A). Laparoscopic right posterior sectionectomy in the left semi-prone position with jack-knife (B).

the right hepatic vein improves as the transection proceeds in a caudal-cranial fashion, with the remnant liver falling away from the resected liver, which remains fixed to the retroperitoneum ${ }^{[45]}$.

This gravitational shift may not be so apparent in cases where the patient is positioned in a left semilateral decubitus or supine with right-sided 30-degree tilt. In these instances, the right lobe of the liver is often fully mobilised to allow for not only the visualisation of the right hepatic vein at its origin, but also to facilitate a better view of the resection plane ${ }^{[46]}$. Full mobilisation allows retraction of the liver anteromedially, such that the resection plane along the right hepatic vein shifts more medially and sits in a vertical axis. Often stay-sutures or rubber-band retraction technique can be utilised on both sides of the resection line to splay open the resection plane and enhance exposure.

\section{Similar right-sided resections performed instead in the semi-prone position}

The surgeon stands on the left cranial side of the patient with the camera assistant on the left caudal side of patient. The first port is placed in the right para-rectal line, $10 \mathrm{~cm}$ below the costal margin. Additional 3 working ports ( 5 or $12 \mathrm{~mm}$ ) are placed in the right pararectal, anterior axillary, and posterior axillary line. An intercostal port in the 7 th intercostal space in the anterior axillary line is inserted for segment 7,8 , and right superior caudate resections [Figure $11 \mathrm{~A}$ ].

A total of 5-6 trocars are utilised in 2 rows. The optical camera utilised in this series is a $5 \mathrm{~mm}$ camera positioned $5 \mathrm{~cm}$ to the right and above the umbilicus, with an additional $12 \mathrm{~mm}$ trocar placed at the right pararectal line at the same level. An upper row of $5 \mathrm{~mm}$ trocars is placed along the right subcostal margin in the right mid-axillary and mid-clavicular line, with an additional $12 \mathrm{~mm}$ sub-xiphoid trocar. Dissection similarly begins with hilar inflow control of the posterior sectoral and thereafter full right lobe mobilisation followed by parenchyma transection [Figure 11B].

\section{LESS COMMONLY EMPLOYED SURGICAL APPROACHES}

\section{Trans-diaphragmatic thoracoscopic approach}

Trans-thoracic trans-diaphragmatic surgical approach has also been described for lesions in the dome of the liver ${ }^{[12,47-49]}$. This technique involves port placements into the thoracic cavity followed by trans- 
diaphragmatic ultrasonographic localisation of the liver tumor, followed by incision of the diaphragm. It entails single lung ventilation and placement of a chest drain at the end of surgery after repair of the diaphragm, and should ideally only be utilised for superficial resections that are not close to major hepatic veins. The single lung ventilation maximises the working space of thoracoscopic instruments without the use of carbon dioxide insufflation.

A pure thoracoscopic approach may be particularly useful in patients with multiple previous abdominal surgeries so as to avoid difficult adhesiolysis in the scarred abdomen ${ }^{[49]}$. However, if there is a need to access the porta hepatis and hepatoduodenal ligament for the Pringle manoeuvre as well as survey the left lobe of the liver with intra-operative ultrasound, the surgery can be modified to involve two steps with an anterior trans-abdominal approach in the supine position followed by left lateral positioning with transthoracic approach $^{[47]}$. In this approach, the pneumoperitoneum is evacuated prior to transthoracic port placement and diaphragmatic incision.

Understandably, this trans-thoracic surgical approach raises concerns for potential thoracic complications such as bilio-pleural fistula, oncological compromise, atelectasis, pneumothorax, and diaphragmatic hernia.

\section{Hand-assisted laparoscopic approach}

The adoption of hand-assisted laparoscopic surgery (HALS) for the liver is largely dependent on surgeon preference and type of resection planned. It may be utilised more for hemi-hepatectomies, whereby the hand-port incision serves a dual purpose for specimen extraction. It is also viewed by some as an interim approach for surgeons in their early experience with LLR as the hand-port can be used to facilitate liver retraction along the parenchymal cut line. The hand-port also allows for immediate compression or elevation whenever bleeding is encountered and provides tactile feedback in assessing tumor margins ${ }^{[50]}$.

\section{HALS right and left hepatectomy described by University of Pittsburgh Medical Center ${ }^{[51,52]}$}

The patient is positioned supine. The hand-port is placed at the start of the operation and when it is not utilised, a $12 \mathrm{~mm}$ trocar is inserted through the gelport.

The main surgeon stands on patient's left side [Figure 12A].

The main surgeon stands on the patient's right side. The hand-port is placed lower so as to minimize conflict with the laparoscopic instruments [Figure 12B].

\section{Single-incision laparoscopy approach}

Single port laparoscopic hepatectomies have also been described, most frequently but not exclusively for minor hepatectomies such as left lateral sectionectomy and wedge resections ${ }^{[53-56]}$. A trans-umbilical incision is typically performed ranging between $4-5 \mathrm{~cm}$ and limited to lesions that are not larger than $5 \mathrm{~cm}$. In LLR involving postero-superior lesions, the incision may need to be modified to a right upper quadrant transverse incision to allow laparoscopic instruments to reach the dome of the liver ${ }^{[54]}$. Limitations of SILS include lack of triangulation, which adds challenge to the surgery and as such, may only be recommended for experienced surgeons in select cases.

\section{CONCLUSION}

With increasing access and advancements in minimally invasive equipment, an increasing proportion of liver surgeons will adopt LLR as a routine and push boundaries to complete more challenging resections using a pure laparoscopy approach ${ }^{[57]}$. Whilst established frameworks in patient and port positioning exist, liver surgeons should still aim to be flexible, modifying approaches according to patient's physique, tumour size and location, as well as the underlying liver pathology. The LLR learning curve can be steep and the 

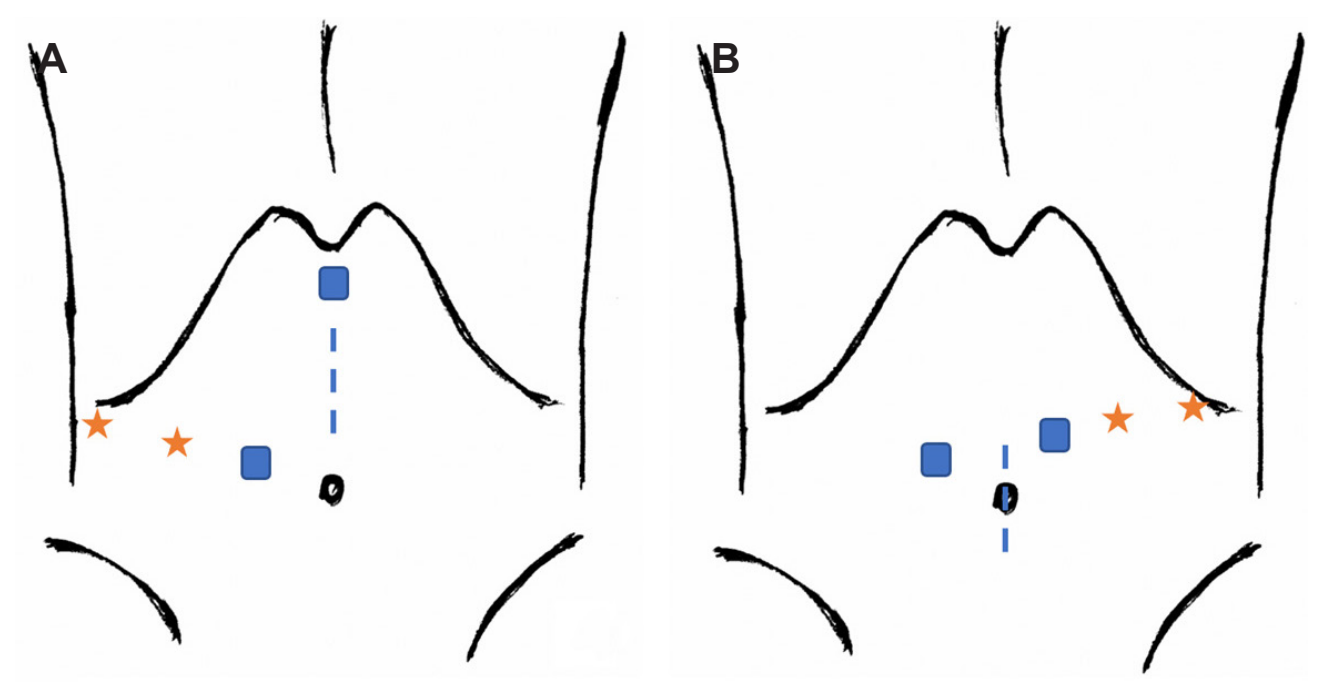

$12 \mathrm{~mm}$ working ports

$\star 5 \mathrm{~mm}$ port

Hand-port

Figure 12. Hand-assisted laparoscopic approach for right and left hepatectomy. Hand-assisted right hepatectomy (A). Hand-assisted left hepatectomy (B).

application of existing LLR difficulty scores will help surgeons tailor their level of experience accordingly, to the appropriate resection that they should embark on safely ${ }^{[58-61]}$. Another guiding tool that is important, yet under-described, is the art and science of optimal patient and port positioning.

Currently, three-dimensional (3D) simulation software such as SYNAPSE VINCENT volume analyzer (Fujifilm Co., Tokyo, Japan) allows conversion of computer tomography liver images into 3D imagery, facilitating precise and parenchymal-saving resections by providing a detailed analysis of subsegmental inflow vessels and venous drainage. Moreover, real-time virtual sonography (RVS) provides a reconstructed CT image, which can be utilised to precisely identify structures in the planned resection line and ensure safe resection margins. Looking forward, a technology that may potentially enhance LLR is the use of 3D virtual resection planning integrated with augmented reality (AR), such that surgeons can be provided with imagery that is transposed live into the operative field. At the current moment, the use of AR as an intraoperative navigation tool is limited because reference CT or $3 \mathrm{D}$ images are rigid and unable to synchronize accurately with the natural deformation of liver parenchyma that occurs during liver mobilisation and parenchymal transection. Hallet et al. ${ }^{[48]}$ describe the use of AR for trans-thoracic trans-diaphramatic resection of a dome lesion that involved minimal liver deformation, and hence facilitated ideal intercostal port placement and precise diaphragmatic incisions. As technology advances in the future, it may allow for enhanced planning of patient positioning and port placements, and facilitate more precise parenchymal resections.

\section{DECLARATIONS}

\section{Acknowledgments}

The authors acknowledge Mr Ravin Thiruchelvam (ravin.light@gmail.com) for image editing.

\section{Authors' contributions}

Made substantial contributions to conception of the article, drafting of the article and material support: Thiruchelvam N 
Made substantial contributions to conception of the article, material support and substantive revision: Lee SY, Chiow AKH

\section{Availability of data and materials}

Not applicable.

\section{Financial support and sponsorship}

None.

\section{Conflicts of interest}

All authors declared that there are no conflicts of interest.

\section{Ethical approval and consent to participate}

Not applicable.

\section{Consent for publication}

Not applicable.

\section{Copyright}

(c) The Author(s) 2021.

\section{REFERENCES}

1. Buell JF, Cherqui D, Geller DA, et al; World Consensus Conference on Laparoscopic Surgery. The international position on laparoscopic liver surgery: The Louisville Statement, 2008. Ann Surg 2009;250:825-30.

2. Wakabayashi G, Cherqui D, Geller DA, et al. Recommendations for laparoscopic liver resection: a report from the second international consensus conference held in Morioka. Ann Surg 2015;261:619-29.

3. Hibi T, Cherqui D, Geller DA, Itano O, Kitagawa Y, Wakabayashi G. Expanding indications and regional diversity in laparoscopic liver resection unveiled by the International Survey on Technical Aspects of Laparoscopic Liver Resection (INSTALL) study. Surg Endosc 2016;30:2975-83.

4. Goh BKP, Lee SY, Teo JY, et al. Changing trends and outcomes associated with the adoption of minimally invasive hepatectomy: a contemporary single-institution experience with 400 consecutive resections. Surg Endosc 2018;32:4658-65.

5. Ciria R, Cherqui D, Geller DA, Briceno J, Wakabayashi G. Comparative Short-term Benefits of Laparoscopic Liver Resection: 9000 Cases and Climbing. Ann Surg 2016;263:761-77.

6. Goh BKP, Lee SY, Koh YX, Kam JH, Chan CY. Minimally invasive major hepatectomies: a Southeast Asian single institution contemporary experience with its first 120 consecutive cases. ANZ J Surg 2020;90:553-7.

7. Wakabayashi G, Cherqui D, Geller DA, Han HS, Kaneko H, Buell JF. Laparoscopic hepatectomy is theoretically better than open hepatectomy: preparing for the 2nd International Consensus Conference on Laparoscopic Liver Resection. J Hepatobiliary Pancreat Sci 2014;21:723-31.

8. Soubrane O, Schwarz L, Cauchy F, et al. A conceptual technique for laparoscopic right hepatectomy based on facts and oncologic principles: the caudal approach. Ann Surg 2015;261:1226-31.

9. Goumard C, Farges O, Laurent A,et al. French association for hepatobiliary and pancreatic surgery. an update on laparoscopic liver resection: the French hepato-bilio-pancreatic surgery association statement. J Visc Surg 2015;152:107-12.

10. Gumbs AA, Gayet B. Adopting Gayet's techniques of totally laparoscopic liver surgery in the United States. Liver Cancer 2013;2:5-15.

11. Ishizawa T, Gumbs AA, Kokudo N, Gayet B. Laparoscopic segmentectomy of the liver: from segment I to VIII. Ann Surg 2012;256:95964.

12. Teramoto K, Kawamura T, Takamatsu S, Noguchi N, Nakamura N, Arii S. Laparoscopic and thoracoscopic partial hepatectomy for hepatocellular carcinoma. World J Surg 2003;27:1131-6.

13. Rhu J, Kim SJ, Choi GS, Kim JM, Joh JW, Kwon CHD. Laparoscopic versus open right posterior sectionectomy for hepatocellular carcinoma in a high-volume center: a propensity score matched analysis. World J Surg 2018;42:2930-7.

14. Ikeda T, Mano Y, Morita K, et al. Pure laparoscopic hepatectomy in semiprone position for right hepatic major resection. $J$ Hepatobiliary Pancreat Sci 2013;20:145-50.

15. Ikeda T, Yonemura Y, Ueda N, et al. Pure laparoscopic right hepatectomy in the semi-prone position using the intrahepatic Glissonian approach and a modified hanging maneuver to minimize intraoperative bleeding. Surg Today 2011;41:1592-8.

16. Ikeda T, Toshima T, Harimoto N, et al. Laparoscopic liver resection in the semiprone position for tumors in the anterosuperior and posterior segments, using a novel dual-handling technique and bipolar irrigation system. Surg Endosc 2014;28:2484-92. 
17. Chen JC, Zhang RX, Chen MS, et al. Left jackknife position: a novel position for laparoscopic hepatectomy. Chin J Cancer 2017;36:31.

18. Gobardhan PD, Subar D, Gayet B. Laparoscopic liver surgery: an overview of the literature and experiences of a single centre. Best Pract Res Clin Gastroenterol 2014;28:111-21.

19. Kaneko H, Otsuka Y, Kubota Y, Wakabayashi G. Evolution and revolution of laparoscopic liver resection in Japan. Ann Gastroenterol Surg 2017;1:33-43.

20. Funamizu N, Mishima K, Ozaki T, et al. Pure laparoscopic right hepatectomy for hepatocellular carcinoma with bile duct tumor thrombus (with video). Ann Surg Oncol 2020;28:1511-2.

21. Suh KS, Hong SK, Yi NJ, et al. Pure 3-dimensional laparoscopic extended right hepatectomy in a living donor. Liver Transpl 2016;22:1431-6.

22. Suh KS, Hong SK, Lee KW, et al. Pure laparoscopic living donor hepatectomy: Focus on 55 donors undergoing right hepatectomy. Am $J$ Transplant 2018;18:434-43.

23. Lee JM, Shehta A, Suh KS, et al. Guidance for optimal port placement in pure 3-dimensional laparoscopic donor right hepatectomy. Liver Transpl 2019;25:1714-22.

24. Rhu J, Choi GS, Kim JM, Joh JW, Kwon CHD. Feasibility of total laparoscopic living donor right hepatectomy compared with open surgery: comprehensive review of 100 cases of the initial stage. J Hepatobiliary Pancreat Sci 2020;27:16-25.

25. Rotellar F, Pardo F, Benito A, et al. Totally laparoscopic right hepatectomy for living donor liver transplantation: analysis of a preliminary experience on 5 consecutive cases. Transplantation 2017;101:548-54.

26. Soubrane O, Cherqui D, Scatton O, et al. Laparoscopic left lateral sectionectomy in living donors: safety and reproducibility of the technique in a single center. Ann Surg 2006;244:815-20.

27. Troisi RI, Van Huysse J, Berrevoet F, et al. Evolution of laparoscopic left lateral sectionectomy without the Pringle maneuver: through resection of benign and malignant tumors to living liver donation. Surg Endosc 2011;25:79-87.

28. Kim KH, Jung DH, Park KM, et al. Comparison of open and laparoscopic live donor left lateral sectionectomy. Br J Surg 2011;98:13028.

29. Kim YK, Han HS, Yoon YS, Cho JY, Lee W. Total anatomical laparoscopic liver resection of segment 4 (S4), extended S4, and subsegments S4a and S4b for hepatocellular carcinoma. J Laparoendosc Adv Surg Tech A 2015;25:375-9.

30. Jeung IH, Choi SH, Kim S, Kwon SW. Laparoscopic central bisectionectomy and right anterior sectionectomy using two retraction methods: technical aspects with video. World J Surg 2019;43:3120-7.

31. Choi SH, Choi GH, Han DH, Choi JS. Laparoscopic liver resection using a rubber band retraction technique: usefulness and perioperative outcome in 100 consecutive cases. Surg Endosc 2015;29:387-97.

32. Kim WJ, Kim KH, Shin MH, Yoon YI, Lee SG. Totally laparoscopic anatomical liver resection for centrally located tumors: a single center experience. Medicine (Baltimore) 2017;96:e5560.

33. Ho CM, Wakabayashi G, Nitta H, et al. Total laparoscopic limited anatomical resection for centrally located hepatocellular carcinoma in cirrhotic liver. Surg Endosc 2013;27:1820-5.

34. Lee W, Han HS, Yoon YS, Cho JY, Choi Y, Shin HK. Role of intercostal trocars on laparoscopic liver resection for tumors in segments 7 and 8. J Hepatobiliary Pancreat Sci 2014;21:E65-8.

35. Chiow AK, Lewin J, Manoharan B, Cavallucci D, Bryant R, O’Rourke N. Intercostal and transthoracic trocars enable easier laparoscopic resection of dome liver lesions. HPB (Oxford) 2015;17:299-303.

36. Ogiso S, Conrad C, Araki K, Nomi T, Anil Z, Gayet B. Laparoscopic transabdominal with transdiaphragmatic access improves resection of difficult posterosuperior liver lesions. Ann Surg 2015;262:358-65.

37. Okuda Y, Honda G, Kurata M, Kobayashi S, Sakamoto K, Takahashi K. A safe and valid procedure for pure laparoscopic partial hepatectomy of the most posterosuperior area: the top of segment 7. J Am Coll Surg 2015;220:e17-21.

38. Ichida $\mathrm{H}$, Ishizawa T, Tanaka M, et al. Use of intercostal trocars for laparoscopic resection of subphrenic hepatic tumors. Surg Endosc 2017;31:1280-6.

39. Fuks D, Gayet B. Laparoscopic surgery of postero-lateral segments: a comparison between transthoracic and abdominal approach. Updates Surg 2015;67:141-5.

40. Gumbs AA, Gayet B. Video: the lateral laparoscopic approach to lesions in the posterior segments. J Gastrointest Surg 2008;12:1154.

41. Cheng KC, Yeung YP, Ho KM, Chan FK. Laparoscopic right posterior sectionectomy for malignant lesions: an anatomic approach. $J$ Laparoendosc Adv Surg Tech A 2015;25:646-50.

42. Yoon YS, Han HS, Choi YS, et al. Total laparoscopic right posterior sectionectomy for hepatocellular carcinoma. $J$ Laparoendosc Adv Surg Tech A 2006;16:274-7.

43. Homma Y, Honda G, Kurata M, Ome Y, Doi M, Yamamoto J. Pure laparoscopic right posterior sectionectomy using the caudate lobe-first approach. Surg Endosc 2019;33:3851-7.

44. Schwarz L, Aloia TA, Eng C, Chang GJ, Vauthey JN, Conrad C. Transthoracic port placement increases safety of total laparoscopic posterior sectionectomy. Ann Surg Oncol 2016;23:2167.

45. Tomishige H, Morise Z, Kawabe N, et al. Caudal approach to pure laparoscopic posterior sectionectomy under the laparoscopy-specific view. World J Gastrointest Surg 2013;5:173-7.

46. Cho JY, Han HS, Yoon YS, Choi Y, Lee W. Outcomes of laparoscopic right posterior sectionectomy in patients with hepatocellular carcinoma in the era of laparoscopic surgery. Surgery 2015;158:135-41.

47. Li H, Wei Y, Li B, Peng B. Modified thoracoscopic hepatectomy for segment VIII: a Case Report. Medicine (Baltimore) 2016;95:e3801.

48. Hallet J, Soler L, Diana M, et al. Trans-thoracic minimally invasive liver resection guided by augmented reality. J Am Coll Surg 
2015;220:e55-60.

49. Yamashita S, Loyer E, Kang HC, et al. Total transthoracic approach facilitates laparoscopic hepatic resection in patients with significant prior abdominal surgery. Ann Surg Oncol 2017;24:1376-7.

50. Poultsides G, Brown M, Orlando R 3rd. Hand-assisted laparoscopic management of liver tumors. Surg Endosc 2007;21:1275-9.

51. Cardinal JS, Reddy SK, Tsung A, Marsh JW, Geller DA. Laparoscopic major hepatectomy: pure laparoscopic approach versus handassisted technique. J Hepatobiliary Pancreat Sci 2013;20:114-9.

52. Fiorentini G, Swaid F, Cipriani F, et al. Propensity score-matched analysis of pure laparoscopic versus hand-assisted/hybrid major hepatectomy at two western centers. World J Surg 2019;43:2025-37.

53. Gaujoux S, Kingham TP, Jarnagin WR, D’Angelica MI, Allen PJ, Fong Y. Single-incision laparoscopic liver resection. Surg Endosc 2011;25:1489-94.

54. Shetty GS, You YK, Choi HJ, Na GH, Hong TH, Kim DG. Extending the limitations of liver surgery: outcomes of initial human experience in a high-volume center performing single-port laparoscopic liver resection for hepatocellular carcinoma. Surg Endosc 2012;26:1602-8.

55. Han JH, You YK, Choi HJ, Hong TH, Kim DG. Clinical advantages of single port laparoscopic hepatectomy. World J Gastroenterol 2018;24:379-86.

56. Struecker B, Haber P, Öllinger R, et al. Comparison of single-port versus standard multiport left lateral liver sectionectomy. Surg Innov 2018;25:136-41.

57. Koh YX, Lee SY, Chiow AKH, Kam JH, Goh BKP, Chan CP. Laparoscopic caudate lobe resection: navigating the technical challenge. Ann Laparosc Endosc Surg 2017;2:39.

58. Chiow AKH, Lee SY, Chan CY, Tan SS. Learning curve in laparoscopic liver surgery: a fellow's perspective. Hepatobiliary Surg Nutr 2015;4:411-6.

59. Lee SY, Chiow KH, Goh BKP, Chan CY. The challenge in determining difficulty of laparoscopic liver resection: are we there yet? Laparosc Surg 2018;2:23.

60. Lee SY, Goh BKP, Sepideh G, et al. Laparoscopic liver resection difficulty score-a validation study. J Gastrointest Surg 2019;23:545-55.

61. Goh BKP, Prieto M, Syn N, et al. Validation and comparison of the Iwate, IMM, Southampton and Hasegawa difficulty scoring systems for primary laparoscopic hepatectomies. HPB (Oxford) 2020;S1365-182X(20)31160-6. 